\title{
Historia del silencio. Del renacimiento a nuestros días
}

\author{
Miguel Felipe Dorta Vargas* (D) http://orcid.org/0000-0002-5693-7826 \\ Instituto de Investigaciones Históricas \\ Universidad Michoacana de San Nicolás de Hidalgo, México \\ ramosucre@gmail.com
}

Alain Corbin, Historia del silencio. Del renacimiento a nuestros días, Barcelona, Acantilado, 2019, 143 pp.

El silencio no ha sido escapatoria del ruido y ha perdido su sacralidad en la actualidad. Con palabras similares el historiador francés Alain Corbin nos traslada a las atmosferas emocionales del silencio y sus imaginarios en la cultura occidental, para dar cuenta de sus características, lecturas, espacios en donde habita, disciplinas y tácticas sobre y con este sujeto histórico, entre otras formas de experimentación humana.

En sus trabajos anteriores (El perfume y el miasma, El territorio del vacío o El mar: terror y fascinación, por nombrar algunos) las percepciones olfativas y auditivas o las contemplaciones de los paisajes, la sexualidad... son vistas como problemas históricos. Es importante recordar que, con el auge del estructuralismo antropológico de Claude Lévi-Strauss y Gaston Bachelard, las sensibilidades y emociones eran miradas como construcciones intemporales e inamovibles, del dominio de los arquetipos

\footnotetext{
* Posdoctorante del Cuerpo Académico "Estudios Latinoamericanos", Programa CA-44, Instituto de Investigaciones Históricas, Universidad Michoacana de San Nicolás de Hidalgo.

(c) (1) (8)

Esta obra está protegida bajo una Licencia Creative Commons Atribución-

No-Comercial 4.0 Internacional.
}

Secuencia. E-ISSN 2395-8464 http://secuencia.mora.edu.mx/

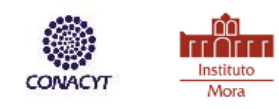


fijos y universales, y fuera del campo de la comprensión histórica (Kalifa, 2019, pp. 4-6). Corbin (2002), discípulo del medievalista Lucien Febvre, plantea que dichas sensibilidades y sus construcciones habían “cambiado [en] las maneras de percibir” y tenían diversas etapas y lecturas en el pasado (p. 9); con lo que introduce el concepto "imaginario social” en vez de mentalidades -dado la dispersión que estas habían creado- para incorporarlo en el movimiento de las sociedades y no la estática en que la antropología estructural lo había ubicado, como lo explica François Hartog (2003) "Se pasa de una historia de las mentalidades a una historia del imaginario” (p. 295). Así, Corbin explica que los afectos y los sentidos olvidados en el tiempo van cobrando importancia en la dinámica en que los individuos, a través de sus formas y prácticas, nutren tanto lo que entiende por real como por "imaginario”.

Historia del silencio, es importante asentar que se trata de ensayo "documentado" que va desde el Renacimiento hasta nuestros días con la finalidad de rastrear históricamente las tramas y los cambios a los que ha sido sujeto el silencio en aquellos "universos mentales desvanecidos” (p. 8). Con una prosa erudita y pausada, Corbin presenta su intención: "Hoy en día, es difícil que se guarde silencio, y ello impide oír la palabra interior que calma y apacigua. La sociedad nos conmina a someternos al ruido para formar así parte de todo, en lugar de mantenernos a la escucha de nosotros mismos.” (p. 8) Metodológicamente hablando, hay dos momentos importantes de rescatar. El primero, que muestra sinceridad ante el problema histórico y las fuentes: "Por desgracia, con respecto a nuestro objetivo, carecemos de testimonios que permitan conocer [las] emociones [...] salvo las que atañen a su búsqueda de Dios” (p. 30), en referencia a las experiencias de los religiosos en el desierto. Y, el segundo, que insiste a los historiadores tener confianza en no "sobreestimar la rareza de la palabra" (p. 109), para poder reconocer los silencios "impuestos, [...] deliberados, [...] implícitos, [...] instrumentalizados y los que resultan de un déficit en el dominio de la enunciación, sin olvidar el rechazo de las elites a registrar la palabra campesina, juzgada de pobre, torpe, incluso incomprensible” (p. 110).

Secuencia. E-ISSN 2395-8464 
Esta obra, que recibió en el 2016 el Premio Roger-Caillois en Francia, consta de ocho capítulos y un postludio que la da por concluida. En el primer capítulo, hace un análisis de aquellos espacios cerrados e íntimos en los que los individuos destinaron su tiempo para guardarse o aislarse; especialmente, las recámaras particulares en los hogares, las que comenzaron a popularizare en la vivienda burguesa, que fueron el deleite de literatos, artistas plásticos y cineastas. También están los claustros y catedrales como cobijo de la comunión espiritual o las cárceles donde el silencio era una imposición. En el segundo capítulo, se encuentran los paisajes de la naturaleza en la que los escritores plasmaron sus emociones vinculadas al silencio de los bosques y campos; la noche y el invierno. No escapó el desierto, aunque las impresiones lo mostraron como "un gran silencio de desolación surgido del despotismo" (p. 31) por los tiránicos regímenes sultánicos. Admiraban los exploradores la "paz" silenciosa de las montañas o en los mares u océanos. Así como el silencio que se conseguía lejos de la ciudad del progreso, en aquellas de características episcopales y provincianas. O, incluso, en las ruinas, donde el silencio pesa como el pasado mismo.

Otro de los temas que analiza el autor son las prácticas del silencio. Especialista en el cristianismo, Corbin ve las transformaciones que tuvieron los ritos entre los siglos XVI y XVII para lograr la "condición necesaria de toda relación con Dios" (p. 51), como las maneras de orar, el tiempo para dedicarse a ello, los horarios, lugares y la introducción del silencio en la mesa a la hora de la comida por Ignacio de Loyola. Igualmente, se centra en las disciplinas del silencio que sirvieron como un mecanismo para "evitar toda agitación” (p. 66) entre los siglos XVIII y XX. Un ejemplo de ello fueron las escuelas secularizadas e ilustradas en las que "callar” era una señal de atención; similar situación en los cuarteles militares. En la vida social, el silencio se impuso a través de los manuales de urbanidad, como el deber de los niños de callar cuando los adultos hablan, controlar las manifestaciones orgánicas del cuerpo o no formar parte del "indecoro" bullicio urbano que generaba las masas populares. En la cuestión punitiva decimonónica, la privación de la palabra se apoyó en las ortopedias para la reinserción social. A Secuencia. E-ISSN 2395-8464 
comienzos del siglo XX la nostalgia del silencio se hizo cada vez mayor y las sensibilidades cotidianas cambiaron en torno a los hábitos como, por ejemplo, el guardar silencio en los trenes o tranvías, los deseos de temperar en las playas o, incluso, los cuidados de enfermos en los consejos de Florence Nightingale.

En su Interludio, Corbin busca “el absoluto del silencio” y considera a José, el padre de Jesús, el "patriarca del silencio": el que calló desde el momento en que apareció en la Biblia hasta su muerte y solo su enseñanza se expresó lejos de la palabra. Lo mismo pasa con Nazaret, aldea que aparece como “el gran tiempo del silencio” (p. 79). Con este apartado el autor busca las representaciones del silencio como verbo; es decir, el regocijo y la reflexión interior que significa. Kierkegaard dijo que el silencio cuando calla también habla y, así, desde la filosofía se ha intentado definir qué representa aquello que el autor llama "la lengua del alma" (p. 81), cuya plenitud da nacimiento a la palabra, entendida como la creatividad y las ideas. También, entre los siglos XVI y XIX, hubo una relación del silencio con la plástica; por ejemplo, la sentencia de Lessing “[la pintura] es poesía muda” (p. 85) o la relación que supo darle Rembrandt entre el vacío, el espacio puro y el silencio (p. 87). Esta admiración al silencio, explica el autor, pasó a las formas en que los espectadores dirigían sus miradas a las pinturas religiosas, ya que en el siglo XIX había una búsqueda de inspiraciones para las prácticas de la piedad; mientras que hoy en día se aprecia en código de reflexión estética; mismo caso que ocurre en el cine mudo, especialmente con la expresión corporal como palabra, con todo aquel sentimiento, ímpetu y emoción de sus personajes.

El viejo refrán "En boca cerrada, no entran moscas" se puede apreciar como una táctica del “arte de callar”, ya que el silencio era visto como una virtud para el secreto o salvar el pellejo. El autor afirma que, de la nutrida edición de textos de esta temática a fines del siglo XVI, la obra capital fue el Oráculo manual y arte de la prudencia (1647) de Baltasar Gracián y sus preceptos fueron un pilar para los moralistas del tránsito de la sociedad cortesana a la burguesa. Un buen ejemplo de ello, fue la tipificación de los silencios que hizo Toussaint Dinouart en su tratado de urbanidad (1771), hay “prudente, artificioso, complaciente, burlón, espiritual, estúpido [y los] de aprobación, de menosprecio, Secuencia. E-ISSN 2395-8464 
de humor, de capricho, de astucia política” (p. 104); los cuales se juntaron, en el siglo XIX, con el tono monocorde, la parquedad o las pequeñas muecas faciales, actos del "arte de callar" expresados en la retórica corporal. Lejos de los miembros de la cúspide, Corbin analiza el silencio de los campesinos, perteneciente al dominio de los secretos: "Disimula los eventuales deseos de venganza. Callar es protegerse de la circulación de los chismorreos del otro" (p. 108), pero también como efecto paralizador ante las autoridades, ricos o foráneos o de camuflaje entre lo callado, lo respetuoso y lo hipócrita ante los agentes o policías.

Lo silente del amor y el odio también es otro tema que se aborda. En las recomendaciones de los moralistas y las sutilidades de los simbolistas decimonónicos, se vio que la palabra no hace falta cuando dos amantes son eclipsados el uno al otro. Lo amoroso se traducía como un profundo silencio, una meditación en la que un suspiro era suficiente, según la novela romántica y kitsch. La misma suerte gozó el placer individual y sus maniobras masturbatorias, en especial la femenina, la cual era conocida como “pequeña muerte”. Pero en el desamor también está, ese odio traducido en distancia que se ve en la ruptura o que está presente en la longevidad; muy bien captado por el realismo social del pintor Edward Hopper.

Corbin ha mostrado el carácter voltario y dual del silencio a lo largo de la obra y finalmente se detiene en los temores que reproduce. Observa que el mutis de Dios en este tiempo (sus últimas palabras las en el bautizo de Jesús) ha sido motivo para endilgarle su trascendencia de ser insoldable, pero también para explicar su ira desmedida e indiferencia. Por mucho tiempo se pensó que se ocultaba mientras sucedían las tragedias y horrores en la humanidad, por lo cual se produjo el reclamo y cuestionamiento de su abandono. Ante esto, Corbin lanza la pregunta conclusiva de su libro: “" $\mathrm{no}$ es la prueba de su inexistencia?” (p. 126). Desde el siglo XIX hasta hoy, la incertidumbre que se consolidó en la Ilustración entre escritores, filósofos y poetas ha ido creciendo y la ausencia de palabra de Dios se ha desdibujado en la literatura, produciendo así su ruptura con la religión. Con las ganas de acabar con ese silente Dios y Secuencia. E-ISSN 2395-8464 
otros temores, quizás, estén las pistas de la presencia de ruido en nuestras vidas, el estruendo de las cotidianidades actuales para aplacar aquellos lugares del silencio que nos invade, sean los del alma o cuando se detiene la "máquina urbana” (p. 132), recordando a Charles Baudelaire. Finalmente, nuestro temor al ineludible silencio prolongado lleva a Corbin a explorar la muerte y sus etapas. La agonía de la enfermedad, con el lecho tenue del que cae en cama; el cuerpo yacente, la casa vacía, y la tumba, fin de la vida consumida y acompañada de otros pares; cuyos sonidos, más allá de los recuerdos en voz alta de los que viven, será el del crecer de los acantos en las canéforas, parafraseando a Rubén Darío.

El silencio no solo ha sido la palabra pronunciada, el estar consigo mismo o la comunión con la entidad suprema religiosa, entre otras, y el tratamiento que hace de sus representaciones da por sentado que hemos cambiado en la manera de convivir con el silencio o con el ruido y que todo dependerá de las inconformidades actuales que tengamos ante ambos. Se extrañaron las fuentes médicas y científicas para tener una visión más amplia, así como también más representaciones del silencio de este otro lado del Atlántico, pero Historia del Silenciono deja de abrir la posibilidad para nuevas investigaciones y, como se dijo en líneas anteriores, la presentación amena de los predios de aquello (que puede significar la nada o el vacío) lo hace de manera magistral la prosa de Corbin.

\section{Referencias}

Corbin, A. (2002). El perfume y el miasma. El olfato y lo imaginario social. Siglo XVIII-XIX. México: Fondo de Cultura Económica.

Hartog, F. (2003). El espejo de Heródoto. Ensayo sobre la representación delotro. Buenos Aires: Fondo de Cultura Económica.

Kalifa, D. (2019). Escribir una historia del imaginario (siglos XIX-XX). Secuencia (105), e1757. doi: https://doi.org/10.18234/secuencia.v0i105.1757 